\title{
INFLUENCE OF POTENTIAL GENE POLYMORPHISMS ON PROPOFOL DOSAGE REGIMEN IN PATIENTS UNDERGOING ABDOMINAL HYSTERECTOMY
}

\author{
Ivanov $\mathrm{E}^{1, *}$, Sterjev $\mathrm{Z}^{2}$, Budic I ${ }^{3}$, Nojkov J ${ }^{4}$, Karadzova D ${ }^{1}$, Sivevski $\mathrm{A}^{1}$ \\ *Corresponding Author: Emilija Ivanov, Prim. M.Med., University Clinic for Gynecology and Obstet- \\ rics, University "Ss Cyril and Methodius" Medical Faculty, Mother Theresa, Skopje, Republic of North \\ Macedonia. Tel./Fax: +389-(0)-23-228-440. E-mail: emilijaivanov@gmail.com
}

\begin{abstract}
Propofol (2,6-diisopropylphenol) is the most common intravenous anesthetic used in modern medicine. It is postulated that individual differences in genetic factors [polymorphism of single nucleotide polymorphisms (SNPs)] in the genes encoding metabolic enzymes, molecular targets and molecular binding sites of propofol can be responsible for susceptibility to propofol effects. The aim of our study was to investigate the influence of the cytochrome P450 2B6 isozyme CYP2B6 (rs3745274), $\gamma$-aminobutyric acid type A (GABAA) receptor $\alpha 1$ subunit GABRA1 (rs2279020) and ATP-binding cassette subfamily B member $1 A B C B 1$ (rs1045642) gene polymorphisms on propofol therapeutic outcomes in the patients undergoing abdominal hysterectomy. Ninety patients aged 29-74 years, with different ethnicities were included in this study. The presence of polymorphisms was analyzed using TaqMan SNP genotype analysis on Stratagene MxPro $3005 \mathrm{P}$ real-time polymerase chain reaction (qPCR). The distribution of all three genetic variants was within the Hardy-Weinberg equilibrium. There was no significant difference $(p>0.05)$ in the allelic frequencies of polymorphic variants and genotype distributions between adult and older patients and between patients of different ethnicities. Our study did not detect a statistically significant influence of the CYP2B6 (c.516G>A), GABRA1 (c.1059+15G>A)
\end{abstract}

\footnotetext{
${ }^{1}$ University Clinic for Gynecology and Obstetrics, University "Ss Cyril and Methodius" Medical Faculty, Skopje, Republic of North Macedonia

${ }^{2}$ Faculty of Pharmacy, University "Ss Cyril and Methodius," Skopje, Republic of North Macedonia

${ }^{3}$ Department of Surgery and Anesthesiology, Medical Faculty, University of Nis, Serbia

${ }^{4}$ Department of Anesthesiology, University "Goce Delcev," Stip, Republic of North Macedonia
}

and $A B C B 1$ (c.3435T $>C$ ) variants on the variability of clinical parameters (doses for induction in anesthesia, additional doses, induction time and wake time after anesthesia and side effects of propofol). However, the observed trend on the possible influence of the $C Y P 2 B 6($ c. $516 \mathrm{G}>\mathrm{A})$ and GABRA1 (c. $1059+15 \mathrm{G}>\mathrm{A}$ ) variants warrant an extension of these studies on a larger number of patients.

Keywords: $A B C B 1$ gene; $C Y P 2 B 6$ gene; GABRA1 gene; Pharmacogenetic; Propofol

\section{INTRODUCTION}

The inter individual variability in response to a drug is quite common and depends on clinical, environmental, social and genetic factors [1]. Pharmacogenetics generally determines variations of a single gene or several genes that influence drug response, while pharmacogenomics indicates drug response variations due to multi gene variations that are encompassed within the whole genome. As a result, gene mutations can potentially affect the response to drugs, which is a common biological phenomenon [2].

Propofol (2,6-diisopropylphenol) is the most common intravenous anesthetic used in modern medicine. Induction in general anesthesia with propofol occurs due to inhibition of $\gamma$-aminobutyric acid type A (GABAA) receptor-mediated neurotransmission [3]. Its significant and prominent use in clinical practice is mainly based on its rapid action, relatively low toxicity, prompt recovery after anesthesia and minimal side effects, even after a long period of anesthesia.

The main metabolic pathway of propofol includes oxidation by the cytochrome P450 2B6 isozyme (CYP2B6), and to a lesser extent cytochrome P450 2C9 isozyme, followed by phase II metabolism by UDP-glucuronosulfotransferase 1A9 (UGT1A9). The cytochrome P450 enzymes (CYP2B6 and CYP2C9) are responsible for the formation of a hydroxyl derivative of propofol- 
4-hydroxypropophol, which can further be transformed into 4-hydroxypropophol-1-ObD-glucuronide (Q1G) and 4-hydroxypropophol-4-ObD-glucuronide (Q4G). About 70.0 to $90.0 \%$ of propofol is eliminated by urine in the form of the glucuronide metabolite $[3,4]$.

It is postulated that individual differences in genetic factors [polymorphism of single nucleotide polymorphisms (SNPs)] in the genes encoding these enzymes can be responsible for susceptibility to propofol effects $[5,6]$. The polymorphism of the CYP $2 B 6$ gene (c.516G $>$ T) decreases the metabolism of propofol and individuals with this polymorphism have been associated with high plasma concentration of propofol [7]. Mutations in genes involved in the molecular targets and molecular binding sites of propofol may also be associated with propofol susceptibility, including the dominant variations (rs2279020) in GABAA receptor $\alpha 1$ subunit GABRA1 gene [8]. The mutation in $\mathrm{P}$-glycoprotein $(\mathrm{P}-\mathrm{gp})$ transporter also known as multi drug resistance $\mathrm{ABC}$ transporter 1 (ABCB1/MDR1), SNP c. 1236 C $>$ T (rs1045642), is partly the reason for single differences in the anesthetic effects [9]. Patients who are homozygous for the $\mathrm{T}$ allele have two to three times less expression of P-gp. This change may result in increased intestinal absorption, decreased renal clearance, or increased brain concentration of various toxic substances [10,11]. This was confirmed in a study of Zhang et al. [9], who found that propofol/remifentanil anesthetic effect following pediatric tonsillectomy in patients with the $\mathrm{CC}$ genotype of MDR1 c.1236C $>$ T (rs1045642) polymorphism was stronger than in those carrying the $\mathrm{CT}+\mathrm{TT}$ genotype. Li et al. [12] found that the $A B C B 1$ (C3435T), did not correlate with efficacy of sufentanil/propofol combination in patients undergoing gynecologic laparoscopic surgery.

Our study aimed to investigate the influence of different SNPs in selected genes on propofol therapeutic outcomes in the patients undergoing abdominal hysterectomy. For that reason, we examined the distribution of the CYP2B6 (rs3745274), GABRA1 (rs2279020) and $A B C B 1$ (rs1045642) gene polymorphisms in our patient group. In this study, we also evaluated the possible influence of these polymorphisms on anesthesia induction time, administered doses of propofol, wake time after surgery and the most common side effects from anesthesia with propofol.

\section{MATERIALS AND METHODS}

This was a prospective study, performed at the Clinic for Gynecology and Obstetrics, University Ss. Cyril and Methodius, and the Center for Biomolecular Pharmaceutical Analysis, Faculty of Pharmacy, University Ss. Cyril and Methodius, Skopje, Republic of North Macedonia, from October 2016 to November 2017. The study complied with the 2013 Declaration of Helsinki and the protocol was approved by the Ethics Committee at the Medical Faculty of Skopje, Ss. Cyril and Methodius University [No. 03-242/1], and the Faculty of Pharmacy, Ss. Cyril and Methodius University [No. 03-51/1]. Ninety patients, scheduled for abdominal hysterectomy, were included in this study. All of them signed informed consent before being enrolled in the study.

Adult and older female patients (from 25 to 75 years), with body weight not above and below $20.0 \%$ of the ideal, and classification status I, II or III, according to the American Society of Anesthesiologists Physical Status Classification System (ASA), were included in the study. The patients were aged 29 to 74 years; median age of $51.5 \pm$ 8.8 years. The body weight varied between 48 and $131 \mathrm{~kg}$; median weight of $77.7 \pm 16.6 \mathrm{~kg}$. Regarding ethnicity, there were 66 Macedonians (73.3\%), 23 Albanians (25.6\%) and one patient of Turkish ethnicity $(1.1 \%)$. According to the ASA physical status classification: nine patients (10.0\%) belonged to the ASA I group, 70 patients $(77.8 \%)$ belonged to the ASA II classification group, and 11 patients (12.2\%) belonged to the ASA III group. Twelve patients (13.3\%) had a history of comorbidities (six with hypertension, three with obesity and diabetes, two with obesity and one with obesity and high blood pressure). Exclusion criteria included: other anesthetics, soy or nut allergies, history of alcohol or drug addiction, chronic diseases such as psychiatric, hepatic or kidney disease.

The propofol was administered according to standard protocol based on individual patients' status and characteristics and evidence-based medicine data obtained from the Summary of Product Characteristics (0.1-0.15 mg/ $\mathrm{kg} / \mathrm{min}$. IV for 3-5 min.). The patients were appropriately preoperatively prepared, and a peripheral intravenous line was inserted before the anesthesia was started. Noninvasive monitoring [arterial tension (TA), electrocardiography (ECG), pulse, oxygen saturation $\left(\mathrm{SpO}_{2}\right)$ and capnography] was used to monitor the vital functions.

In this study, the side effects of propofol, nausea, vomiting and level of sedation, were also analyzed. Recording of side effects started after surgery and ended after 24 hours. The presence of vomiting was noted as number of incidents, while nausea with a nausea score $(0$; no nausea; 1: mild degree; 2 : moderate degree; 3 : severe degree). The sedation was scored according to the Ramsey sedation score (0: awake; 1: anxious and agitated or restless or both; 2: cooperative, oriented and tranquil; 3: responding to commands only; 4: brisk response; 5: sluggish response; 6: no response to stimulus).

General endotracheal anesthesia was performed as follows: introduction $(0.1 \mathrm{mg} / \mathrm{kg}$ midazolam, $2 \mu \mathrm{g} / \mathrm{kg}$ fentanyl, $2 \mathrm{mg} / \mathrm{kg}$ propofol, $0.4-0.6 \mathrm{mg} / \mathrm{kg}$ rocuronium 
bromide; maintenance: rocuronium $0.3 \mathrm{mg} / \mathrm{kg}$, fentanyl 2 $\mu \mathrm{g} / \mathrm{kg}$ and propofol $100 \mathrm{mcg} / \mathrm{kg} / \mathrm{min}$.). At the end of the intervention, reversal of neuromuscular block was achieved with $2.5 \mathrm{mg}$ neostigmine and $1 \mathrm{mg}$ atropine, after which the patients were extubated and taken to a recovery room. The depth of anesthesia was standardized by a method of determining entropy [13]. This method also reduces the incidence of consciousness during general anesthesia. The entropy module is an integral part of the Datex-Ohmeda anesthesia machine. The entropy parameters are: response entropy (RE) values of 0-100 and state entropy (SE) values of 0-91. Response entropy responds rapidly with activation of the facial muscles, while SE is a stable parameter that monitors the hypnotic effect of the applied anesthetic. The SE values are always identical or slightly lower than the RE values. To achieve a unified level of depth of general anesthesia we have always strived to have these values between 40-60 [14].

Genomic DNA was extracted from peripheral blood according to the protocol provided by the manufacturer of the Mag Core HF16 Plus automatic DNA extractor (RBC Bioscience, New Taipei, Taiwan). The presence of CYP2B6 (c.516G $>$ A) (rs3745274, assay ID C_ 7817765 60; Thermo Fisher Scientific Co., Waltham, MA, USA; https:// www.thermofisher.com/order/genome-database/ details/ genotyping/), GABRA1 (c.1059+15G>A) (rs2279020, assay ID__ 15966883 10; Thermo Fisher Scientific Co.) and $A B C B 1$ (c.3435 T>C) (rs1045642, assay ID C__7586657_20; Thermo Fisher Scientific Co.) polymorphisms were analyzed using TaqMan SNP genotype analysis on Stratagene MxPro 3005P real-time polymerase chain reaction (qPCR), apparatus (Agilent Technologies,
Edinburgh, UK) using the protocol recommended by the manufacturer.

The $\chi^{2}$ test was used to compare the observed $v s$. expected genotype frequencies according to Hardy-Weinberg equilibrium. The descriptive statistical analysis was done using the Statistical Package for Social Sciences (SPSS) software version 17 for Windows (www.ibm.com). For the statistical analyses we also used Kolmogorov-Smirnov and Shapiro-Wilk test, $\chi^{2}$ test, Fisher exact test, Student's $t$-test, one-way analysis of variance (ANOVA) (post-hoc Bonferroni test).

\section{RESULTS}

The frequencies of the individual genotypes for each of the polymorphisms examined are given in Table 1. The distribution of all three genetic variants was within the Hardy-Weinberg equilibrium. There was no significant difference $(p>0.05)$ in the allelic frequencies of the $C Y B 2 B 6$, $G A B R A 1$ and $A B C B 1$ gene variants and genotype distributions between adult and older patients and between patients of different ethnicities. Statistically significant differences were not found in the doses of propofol needed for both the induction in anesthesia $(p=0.8)$ and for the additional doses of propofol needed during the anesthesia $(p=0.46)$ among patients with different $C Y P 2 B 6(c .516 \mathrm{G}>\mathrm{A})$ genotypes. The doses of propofol used for the induction of anesthesia were $144.7,140.6$ and $132 \mathrm{mg}$, respectively, while additional doses of propofol administered during the anesthesia were $129.3,146.7$ and $123.3 \mathrm{mg}$, for patients with the GG, GA, and AA genotypes, respectively (Table 2). The results of our study showed no statistically

Table 1. Distribution of the polymorphisms of the examined genes in patients.

\begin{tabular}{|c|c|c|c|c|c|c|c|c|}
\hline \multicolumn{3}{|c|}{ CYP2B6 (c.516G>T) } & \multicolumn{3}{c|}{ GABRA1 (c.1059+15G>A) } & \multicolumn{3}{c|}{ ABCB1 (c.3435T>C) } \\
\hline GG & GT & TT & GG & AG & AA & CC & CT & TT \\
\hline 0.59 & 0.36 & 0.05 & 0.38 & 0.42 & 0.20 & 0.24 & 0.50 & 0.26 \\
\hline
\end{tabular}

Table 2. Correlation of polymorphisms in the $C Y P 2 B 6, G A B R A 1$ and $A B C B 1$ genes and doses of propofol used for the introduction and additional doses during anesthesia.

\begin{tabular}{|l|c|c|c|c|c|c|c|c|c|c|c|c|}
\hline Genes & \multicolumn{9}{c|}{ CYP2B6 (c.516G>T) } & \multicolumn{5}{c|}{ ABCB1 (c.3435T $>$ C) } \\
\hline Alleles $(n)$ & GG (53) & GA (32) & AA (5) & $p$ Value & GG (34) & AG (38) & AA (18) & $p$ Value & TT (23) & CC (22) & CT (45) & $p$ Value \\
\hline Introduction to anesthesia: Propofol (mg) \\
\hline Mean \pm SD & $\begin{array}{c}144.7 \pm \\
40.9\end{array}$ & $\begin{array}{c}141.0 \pm \\
39.9\end{array}$ & $\begin{array}{c}133.9 \pm \\
40.7\end{array}$ & 0.80 & $\begin{array}{c}140.6 \pm \\
40.2\end{array}$ & $\begin{array}{c}138.9 \pm \\
42.0\end{array}$ & $\begin{array}{c}143.2 \pm \\
37.1\end{array}$ & 0.45 & $\begin{array}{c}132.0 \pm \\
47.0\end{array}$ & $\begin{array}{c}152.2 \pm \\
38.2\end{array}$ & $\begin{array}{c}146.7 \pm \\
42.5\end{array}$ & 0.56 \\
\hline Additional dose: Propofol (mg) \\
\hline Mean \pm SD & $\begin{array}{c}129.3 \pm \\
43.6\end{array}$ & $\begin{array}{c}145.0 \pm \\
52.3\end{array}$ & $\begin{array}{c}126.7 \pm \\
47.5\end{array}$ & 0.46 & $\begin{array}{c}146.7 \pm \\
51.6\end{array}$ & $\begin{array}{c}122.4 \pm \\
40.3\end{array}$ & $\begin{array}{c}130.0 \pm \\
48.3\end{array}$ & 0.41 & $\begin{array}{c}12.3 \pm \\
68.1\end{array}$ & $\begin{array}{c}144.4 \pm \\
52.7\end{array}$ & $\begin{array}{c}140.4 \pm \\
48.3\end{array}$ & 0.57 \\
\hline
\end{tabular}

SD: standard deviation.

a The $p$ value was determined by the Kruskal-Wallis test. 
significant difference on the induction time $(p=0.59)$ and awakening time $(p=0.06)$ between patients with different CYP2B6 (c.516G $>$ A) genotypes, although there was a trend of shorter time for both parameters in patients with an A allele. The longest induction and awakening times were recorded in patients with GG genotype (96.7 and 15.4 seconds, respectively), followed by patients with GA (73.75 and 12.6 seconds, respectively) and AA genotypes (54.0 and 11.0 seconds, respectively) (Figure 1).

The results on the possible influence of the GABRA1 (c. $1059+15 \mathrm{G}>\mathrm{A}$ ) polymorphism on the doses for induction and maintenance of anesthesia and times for induction and awakening showed no statistically significant difference $(p$ $>0.05$ for all comparisons). On average, patients with the GG genotype received $141 \mathrm{mg}$ of propofol, whereas the average doses for patients with the AG and AA genotype were 138.9 and $152.2 \mathrm{mg}$, respectively $(p=0.45)$ (Table 2 ).

No statistically significant differences were observed in the doses of propofol on induction and awakening times between patients with different GABRAl (c.1059+15G $>\mathrm{A})$ genotypes ( $p=0.54$ and $p=0.7$, respectively) (Figure 2). Regarding the $A B C B 1$ (c.3435T $>C$ ) polymorphism, it was observed that the doses of propofol used for the intravenous anesthesia in patients with the TT genotype (134.0 mg) were lower than the doses administered to patients with CC and CT genotypes (143.2 and $146.7 \mathrm{mg}$, respectively). However, this difference did not reach a statistical significance $(p=0.56)$ (Table 2$)$. There were also no statistically significant differences both in the number of patients who needed additional doses of propofol [12 $(52.2 \%), 10(45.45 \%)$ and $24(53.3 \%)$ patients with TT, $\mathrm{CC}$ and CT genotypes, respectively] and in the doses administered as intraoperative supplementation [126.7, 130 and $140.4 \mathrm{mg}$ in patients with CC, CT and TT genotypes, respectively $(p=0.8)]$. No differences were observed in the induction $(p=0.16)$ and awakening $(p=0.86)$ times between patients with different $A B C B 1$ genotypes (60.0, and 89.5 and 97.8 seconds for induction and 13.7, 14.3 and 14.3 seconds for awakening for patients with TT, CT and $\mathrm{CC}$ genotypes, respectively) (Figure 3).

The most common side effects associated with the use of propofol in our study group were nausea, vomiting and level of sedation. We did not find statistically significant differences among these side effects and different genotypes for the examined polymorphisms. The frequencies of these side effects correlated with the different genotypes as shown in Table 3.

\section{DISCUSSION}

In this study, we evaluated the possible influence of three functional SNPs in genes with potential influence on propofol pharmacokinetics and/or pharmacodynamics, and therefore, on dose requirements for achieving adequate propofol response. The study was undertaken in a relatively homogenous group of patients (according to the ASA physical status classification), who required treatment at a single University Hospital Clinic, with a

Table 3. The most common side effects of Propofol in correlation with different genotypes.

\begin{tabular}{|l|c|c|c|c|c|c|c|c|c|c|c|c|}
\hline \multicolumn{1}{|c|}{ Genes } & \multicolumn{4}{|c|}{ CYP2B6 (c.516G>T) } & \multicolumn{3}{c|}{ GABRA1 (c.1059+15G>A) } & \multicolumn{4}{c|}{ ABCB1 (c.3435T>C) } \\
\hline Alleles $(n)$ & GG (53) & GT (32) & TT (5) & $p$ Value & GG (34) & AG $(38)$ & AA $(18)$ & $p$ Value & TT (23) & CC (22) & CT (45) & $p$ Value \\
\hline Nausea & $n(\%)$ & $n(\%)$ & $n(\%)$ & & $n(\%)$ & $n(\%)$ & $n(\%)$ & & $n(\%)$ & $n(\%)$ & $n(\%)$ & \\
\hline score 0 & $51(96.22)$ & $30(93.74)$ & $5(100.0)$ & 0.74 & $32(94.12)$ & $36(94.74)$ & $18(100.0)$ & 0.54 & $23(100.0)$ & $21(95.45)$ & $42(93.33)$ & 0.52 \\
\hline score 1 & $1(1.89)$ & $0(0.0)$ & $0(0.0)$ & & $0(0.0)$ & $1(2.63)$ & $0(0.0)$ & & $0(0.0)$ & $1(4.55)$ & $0(0.0)$ & \\
\hline score 2 & $1(1.89)$ & $1(3.13)$ & $0(0.0)$ & & $2(5.88)$ & $0(0.0)$ & $0(0.0)$ & & $0(0.0)$ & $0(0.0)$ & $2(4.44)$ & \\
\hline score 3 & $0(0.0)$ & $1(3.13)$ & $0(0.0)$ & & $0(0.0)$ & $1(2.63)$ & $0(0.0)$ & & $0(0.0)$ & $0(0.0)$ & $1(2.22)$ & \\
\hline Vomiting & & & & & & & & & & & & \\
\hline$\# 0$ & $52(98.11)$ & $30(93.74)$ & $5(100.0)$ & 0.55 & $32(94.12)$ & $37(97.37)$ & $18(100.0)$ & 0.33 & $23(100.0)$ & $22(100.0)$ & $42(93.33)$ & 0.75 \\
\hline$\# 1$ & $1(1.89)$ & $1(3.13)$ & $0(0.0)$ & & $2(5.88)$ & $0(0.0)$ & $0(0.0)$ & & $0(0.0)$ & $0(0.0)$ & $2(4.44)$ & \\
\hline$\# 2$ & $0(0.0)$ & $1(3.13)$ & $0(0.0)$ & & $0(0.0)$ & $1(2.63)$ & $0(0.0)$ & & $0(0.0)$ & $0(0.0)$ & $1(2.22)$ & \\
\hline Sedation & & & & & & & & & & & \\
\hline score 0 & $46(86.79)$ & $32(100.0)$ & $5(100.0)$ & 0.69 & $31(91.18)$ & $34(89.47)$ & $18(100.0)$ & 0.96 & $21(91.30)$ & $21(95.45)$ & $41(91.11)$ & 0.88 \\
\hline score 1 & $1(1.89)$ & $0(0.0)$ & $0(0.0)$ & & $0(0.0)$ & $1(2.63)$ & $0(0.0)$ & & $0(0.0)$ & $0(0.0)$ & $1(2.22)$ & \\
\hline score 2 & $3(5.66)$ & $0(0.0)$ & $0(0.0)$ & & $2(5.88)$ & $1(2.63)$ & $0(0.0)$ & & $1(4.35$ & $0(0.0)$ & $2(4.44)$ & \\
\hline score 3 & $2(3.77)$ & $0(0.0)$ & $0(0.0)$ & & $1(2.94)$ & $1(2.63)$ & $0(0.0)$ & & $1(4.35)$ & $1(4.55)$ & $0(0.0)$ & \\
\hline score4 & $1(1.89)$ & $0(0.0)$ & $0(0.0)$ & & $0(0.0)$ & $1(2.63)$ & $0(0.0)$ & & $0(0.0)$ & $0(0.0)$ & $1(2.22)$ & \\
\hline
\end{tabular}




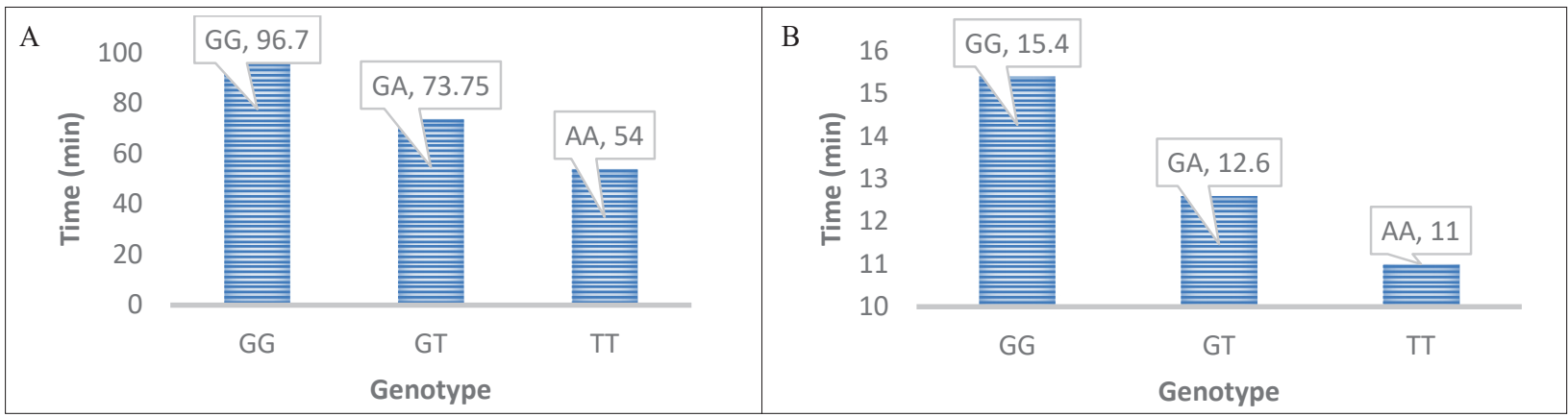

Figure 1. Correlation of the CYP2B6 (c.516G $>$ A) genotype and times for anesthesia induction (A) and awakening (B).

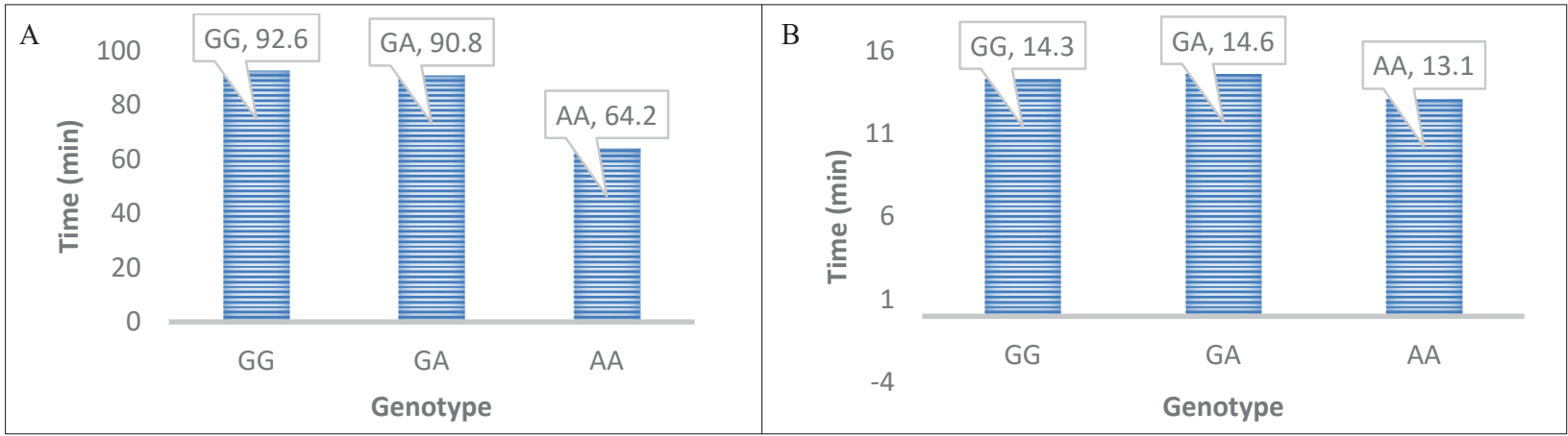

Figure 2. Correlation of the GABRA (c.1059+15G>A) genotype and times for anesthesia induction (A) and awakening (B).

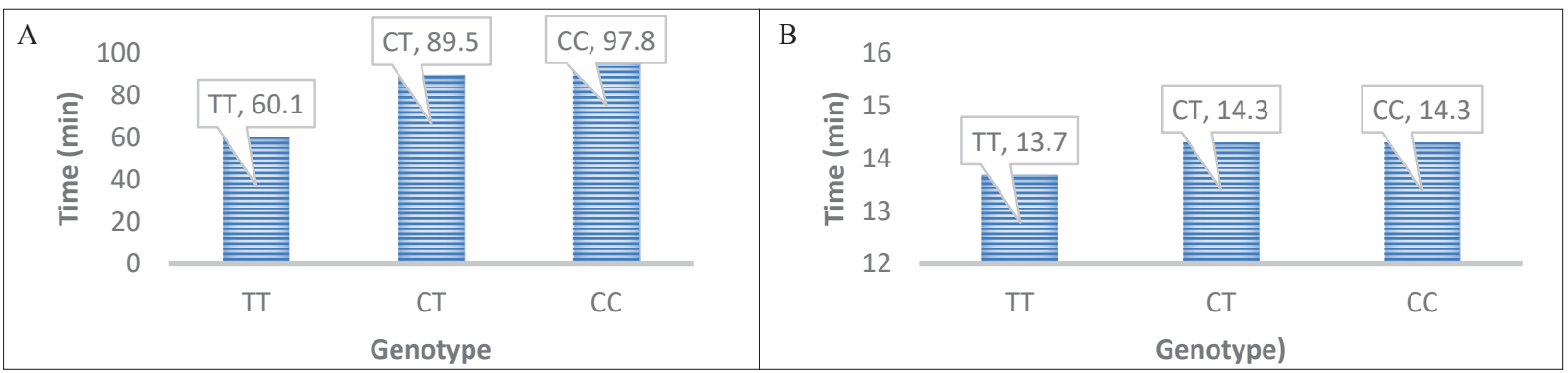

Figure 3. Correlation of the $A B C B 1$ (c.3435T $>$ C) genotype and times for anesthesia induction (A) and awakening (B).

strict follow-up of clinical guidelines for administration of recommended doses of other medications to achieve the same level of anesthesia depth in all subjects.

The results of previous studies evaluating the association of individual genetic characteristics of patients with the dosage and effects of propofol treatment suggest a possible association of polymorphisms in certain genes with the use of propofol in daily clinical practice. Conflicting data have been reported from the clinical studies that evaluated polymorphisms in genes encoding enzymes involved in propofol metabolism (CYP2C9, CYP2B6, CYP3A4, UGT1A9) as well as polymorphisms in genes encoding (GABRA1) receptor protein and transport protein gene $A B C B 1[13,14]$. Our study aimed at contributing to the knowledge on the influence of several SNPs in $C Y P 2 B 6, G A B R A 1$, and $A B C B 1$ genes on variations in the clinical response of propofol.
The $C Y P 2 B 6$ is one of the most polymorphic $C Y P$ genes in humans. Variants of this gene have been shown to affect transcriptional regulation, protein expression and catalytic activity [15]. Some variations seem to affect several functional levels simultaneously, and thus, combined in haplotypes, lead to complex interactions between substrate-dependent and independent mechanisms. Polymorphism c.516>GT (rs3745274, Gln172His) presents a modified rearrangement site that results in loss of exons 4 to 6 , leading to a drastic reduction in normal transcripts and a reduced level of active protein. All this leads to a reduced metabolism rate of propofol. Our results indicate that patients with one or two copies of the variant allele require lower doses of propofol for the induction and maintenance of anesthesia. We also found that times for induction and awakening are different among patients 
with different genotypes for this metabolism. However, these differences were not statistically significant, most probably due to the small number of patients in our cohort. These data are in agreement with the results obtained by Mourão et al. [7], who also found the possible influence of the CYP2B6 (c.516G $>\mathrm{T})$ genetic variant on propofol dose in patients under general anesthesia. A larger study to clarify this issue is warranted, as it might help in the stratification of patients for propofol use during anesthesia.

The GABRAl gene encodes a $\gamma$-aminobutyric acid (GABA) receptor. The GABA receptor is the major inhibitory neurotransmitter in the mammalian brain where it acts at a GABAA receptor, which are ligand-gated chloride channels. The GABRA1 gene mutation leads to the formation of an abnormal $\alpha 1$ subunit that reduces the GABAA receptor protein function. The $\mathrm{G}>\mathrm{A}$ mutation in rs2279020 on the GABRA1 gene may be able to alter the pharmacological properties of the receptor by altering the composition and distribution of subunits. Under propofol anesthesia, small A-allelic rs2279020 in GABAA1 can induce stronger brain inhibition, as seen through entropy in patients after loss of consciousness $[16,17]$. This result strongly supports the role of GABAA1 in the sensitivity of propofol anesthesia. Moreover, the GABAA1 receptor mutation (rs2279020) also contributes to the different effects of propofol on blood pressure. The detected genotypic frequencies for GABRA1 (rs2279020, assay ID C_15966883_10) in our patients group were $38.0 \%$ for $\mathrm{GG}, 42.0 \% \mathrm{AG}$ and $20.0 \%$ for AA. Our results have shown that the frequency of these polymorphisms in our patients is similar to that in other population studies [18]. In our study, we found differences between the given propofol doses in patients with different genotype for the polymorphism studied. In the case of the GABRE polymorphism examined, this trend is much more intense compared to the $C Y P 2 B 6$ gene trend, but still insufficient to obtain a statistically significant difference, which in our opinion, is due solely to the number of patients included.

The $A B C B 1$ (MDR1, P-gp) gene is the first identified and best characterized $\mathrm{ABC}$ transporter. This gene encodes for a transmembrane protein that mediates ATP-dependent transport of various molecules. The P-gp is the "guardian" of the brain and is expressed in the luminal surface of the blood-brain barrier (BBB) capillary endothelial cells. It enables the transport of toxic compounds out of the brain. The exon 26 c. $3435 \mathrm{C}>\mathrm{T}$ variant is one of the more than 100 polymorphic variants of this gene that have been discovered so far. This polymorphism correlates with altered levels of P-gp expression and a change in drug response in various clinical conditions [19]. Our data indicates that the $A B C B 1$ (c.3435C $>\mathrm{T}$ ) variant does not have any influence of the clinical parameters in our cohort of patients who received propofol for anesthesia. Although there are limited data about the influence of this variant on propofol therapy, our data is in line with the result published by Zakerska-Banaszak et al. [20], who also failed to find statistically significant difference between the propofol therapeutic effects and the $A B C B 1$ gene variants.

In conclusion, our study did not detect a statistically significant influence of the CYP2B6 (c.516G >A), GABRA1 (c. $1059+15 \mathrm{G}>\mathrm{A})$ and $A B C B 1$ (c.3435T $>\mathrm{C})$ gene variants on the variability of clinical parameters associated with the use of propofol. We also did not see a statistically significant difference when we grouped patients by age or ethnicity. However, the observed trend on the possible influence of the CYP2B6 (c.516G $>\mathrm{A})$ and GABRA1 (c. $1059+15 \mathrm{G}>\mathrm{A}$ ) variants warrant an extension of these studies on a larger number of patients $[7,8,21]$.

Declaration of Interest. The authors report no conflicts of interest. The authors alone are responsible for the content and writing of this article.

\section{REFERENCES}

1. Behrooz A. Pharmacogenetics and anaesthetic drugs: Implications for perioperative practice. Ann Med Surg (Lond). 2015; 4(4): 470-474.

2. Maitland-van der Zee A-H, Klungel OH, De Boer A. Pharmacogenetics in health-care practice. Pharm World Sci. 2004; 26(5): 253-255.

3. Butterworth JF, Mackey DC, Wasnick JD. Morgan \& Mikhail's Clinical Anesthesiology, 5th ed. New York, NY, USA: Lange Medical Books/McGraw Hill Medical Publishing Division; 2013.

4. Chidambaran V, Ngamprasertwong P, Vinks AA, Sadhasivam S. Pharmacogenetics and anesthetic drugs. Curr Clin Pharmacol. 2012; 7(2): 78-101.

5. Pavlovic D, Budic I, Jevtovic Stoimenov T, Stokanovic D, Marjanovic V, Stevic M, et al. The effect of UGT1A9, CYP2B6 and CYP2C9 genes polymorphism on propofol pharmacokinetics in children. Pharmgenomics Pers Med. 2020; 13: 13-27.

6. Mikstacki A, Skrzypczak-Zielinska M, Tamowicz B, Zakerska-Banaszak O, Szalata M, Slomski R. The impact of genetic factors on response to anaesthetics. Adv Med Sci. 2013; 58(1): 9-14.

7. Mourão AL, de Abreu FG, Fiegenbaum M. Impact of the cytochrome P450 2B6 (CYP2B6) gene polymorphism c.516G $>$ T (rs3745274) on propofol dose variability. Eur J Drug Metab Pharmacokinet. 2016; 41(5): 511-515. 
8. Zhong Q, Chen X, Zhao Y, Liu R, Yao S. Association of polymorphisms in pharmacogenetic candidate genes with propofol susceptibility. Sci Rep. 2017; 7(1): 3343.

9. Zhang Y, Li Y, Wang H, Cai F, Shen S, Luo X. Correlation of MDR1 gene polymorphism with propofol combined with remifentanil anesthesia in pediatric tonsillectomy. Oncotarget. 2017; 9(29): 2029420303.

10. Galinkin JL, Demmer L, Yaster M. Genetics for the pediatric anesthesiologist: A primer on congenital malformations, pharmacogenetics, and proteomics. Anesth Analg. 2010; 111(5): 1264-1274.

11. Takashina Y, Naito T, Mino Y, Yagi T, Ohnishi K, Kawakami J. Impact of CYP3A5 and ABCB1 gene poly-morphisms on fentanyl pharmacokinetics and clinical responses in cancer patients undergoing conversion to a transdermal system. Drug Metab Pharmacokinet. 2012; 27(4); 414-421.

12. Li H-B, Lin R, Zhou X-J, Li W, Liu Z-Q, Zhu L-P. Effects of OPRM1, ABCB1 and CYP2D6 single nucleotide polymorphisms on clinical efficacy of sufentanil-propofol anesthesia in patients undergoing gynecologic laparoscopic surgery: A preliminary study. Int J Clin Exp Med. 2016; 9(12): 23048-23059.

13. Lian QQ, Pan PP, Li JW, Lin H, Hu GX, Zuo MZ, et al. Impact of CYP2C9 polymorphism found in the Chinese population on the metabolism of propofol in vitro. Biol Pharm Bull. 2015; 38(4): 531-535.

14. Choong E, Loryan I, Lindqvist M, Nordling Å, el Bouazzaoui S, van Schaik RH, et al. Sex difference in formation of propofol metabolites: A replication study. Basic Clin Pharmacol Toxicol. 2013; 113(2): 126-131.
15. Zanger UM, Klein K. Pharmacogenetics of cytochrome P4502B6 (CYP2B6): Advances on polymorphisms, mechanisms, and clinical relevance. Front Genet. 2013; 4: 24.

16. Schmidt GN, Bischoff P, Standl T, Hellstern A, Teuber O, Schulte Esch J. Comparative evaluation of the Datex-Ohmeda S/5 Entropy Module and the Bispectral Index monitor during propofol-remifentanil anesthesia. Anesthesiology. 2004; 101(6): 1283-1290.

17. White PF, Tang J, Romero GF, Wender RH, Naruse $\mathrm{R}$, Sloninsky A, et al. A comparison of state and response entropy versus bispectral index values during the perioperative period. Anesth Analg. 2006; 102(1): 160-167.

18. Richardson, JE, Garcia PS, O'Toole KK, Derry JM, Bell SV, Jenkins A. A conserved tyrosine in the beta2 subunit M4 segment is a determinant of gamma-aminobutyric acid type A receptor sensitivity to propofol. Anesthesiology. 2007; 107; 412-418.

19. Fung KL, Gottesman MM A synonymous polymorphism in a common MDR1 (ABCB1) haplotype shapes protein function. Biochim Biophys Acta. 2009; 1794(5): 860-871.

20. Zakerska-Banaszak O, Skrzypczak-Zielinska M, Tamowicz B, Mikstacki A, Walczak M, Prendecki $\mathrm{M}$, et al. Longrange PCR-based next-generation sequencing in pharmacokinetics and pharmacodynamics study of propofol among patients under general anaesthesia. Sci Rep. 2017; 7: 15399.

21. Iohom G, Ni Chonghaile M, O’Brien JK, Cunningham AJ, Fitzgerald DF, Shields DC. An investigation of potential genetic determinants of propofol requirements and recovery from anaesthesia. Eur J Anaesthesiol. 2007; 24(11): 912-919. 